\title{
DEVELOPMENT OF HYBRID AMMONIA ABSORPTION REFRIGERATOR BY GAS ENGINE EXHAUST HEAT
}

\author{
Hiroumi Fujimoto* and Toshio Nishida** \\ * R \& D Dept., Osakagas CO., LTD., 6-19-9, Torishima, Konohana-ku, Osaka, Japan \\ **Engineering Dept., Osakagas CO., LTD., 11-61,Torishima, Konohana-ku, Osaka, Japan
}

\begin{abstract}
Conventional gas engine exhaust heat absorption chiller, which is often used for space cooling, can not make temperature below $-10^{\circ} \mathrm{C}$, because the driving temperature of the jacket water is too low for the purpose. Although it can make temperature below $-10^{\circ} \mathrm{C}$ if driven by high temperature steam extracted from the exhaust gas boiler, the cooling capacity becomes very small in such a case. A hybrid refrigeration system has been newly developed to overcome this problem. The system is a turbo-charger integrated absorption system in which the compressor of $135,000 \mathrm{rpm}$ transfers the refrigerant from evaporator to absorber. The turbine is driven by $3 \mathrm{MPa}$ vapor from exhaust gas boiler, while the jacket water, together with the spent vapor after turbine, regenerates the refrigerant. It has been proven that the capacity of the developed system is about the twice of above mentioned steam-driven conventional chiller.
\end{abstract}

Keywords: Co-generation, Gas Engine, Exhaust Heat, Ammonia, Refrigerator

\section{INTRODUCTION}

To increase the utilization efficiency of co-generation, it is important to transform the exhaust heat to the useful energy the site needs. In the previous paper [1], one of the authors proposed a turbocharger integrated absorption system to make cold energy of $-20^{\circ} \mathrm{C}$, in which, to enable the system, a compressor is directly connected to $\mathrm{NH}_{3}$ vapor turbine. The compressor transfers the $\mathrm{NH}_{3}$ refrigerant forcibly from the evaporator to the absorber. One of the big differences of our system from other hybrid systems proposed before [2][3] is that it is driven by two gas engine exhaust heats and, except pumps, it needs neither electricity nor fuel gas. Using latter valuable energy jeopardizes the efficiency as well as running cost; there are lots of better alternative conventional methods in such a case. However in the new system, the adoption of high performance turbocharger is indispensable to ensure the high performance and it requires some techniques to deal with its peculiar characteristics. The turbine vapor is supplied from exhaust gas boiler and the spent vapor after turbine is reused to drive the regenerator, together with jacket water.

To show the effectiveness of the proposal, the authors have developed a test system in the course of 3 years project, financially assisted by NEDO. It has been proved that the refrigeration capacity is almost twice as large as ordinary absorption system, which uses only the high temperature portion of the exhaust gas.

Based on test results, extension of the concept to space cooling/heating is also investigated by simulation. It is shown that, if the refrigerator is used as a chiller for space cooling, COP is expected to be 0.82 . It is also shown that the proposed system can be used as a heat pump, while conventional single effect absorption chiller cannot be used for the purpose. In this case, COP is expected to be 1.62 at the output temperature of $41.5^{\circ} \mathrm{C}$ and 1.35 at the output temperature of $50^{\circ} \mathrm{C}$.

\section{CONVENTIONAL ABSORPTION CHILLER}

Gas engine has two exhaust heat sources. One is exhaust gas of about $500^{\circ} \mathrm{C}$ and the other is jacket water of about $90^{\circ} \mathrm{C}$. When conventional exhaust heat absorption chiller for space cooling is applied to gas engine co-generation, jacket water is, usually after reheated by the exhaust gas, introduced to the regenerator of the chiller. In the conventional chiller, ammonia-water mixture in absorber is transferred to regenerator, where jacket water segregates $\mathrm{NH}_{3}$ vapor. The segregated $\mathrm{NH}_{3}$ is then condensed in condenser and introduced to evaporator where cold energy is produced. Finally, the evaporated $\mathrm{NH}_{3}$ is absorbed into the lean ammonia-water mixture in absorber to repeat the cycle

This system is simple but has the following defect in view of energy saving.

(1) As the exhaust gas heat of high temperature is transferred to the jacket water of low temperature before it is introduced to the chiller, big exergy loss takes place. (2) Lower temperature portion of exhaust gas than jacket water cannot be recovered. 
Furthermore, this system cannot produce cold energy below $-10^{\circ} \mathrm{C}$. The reason is as follows. The pressure in the absorber, which is a function of $\mathrm{NH}_{3}$ concentration and the temperature (almost equal to the cooling water temperature), is slightly lower than that in evaporator. The driving force to transfer the vapor refrigerant is the difference of the $\mathrm{NH}_{3}$ concentration between the absorber and the evaporator, which is made by the exhaust heat of jacket water. However, when the temperature in the evaporator decreases, the liquid in the absorber can no more absorbs the refrigerant. To enable the absorption, leaner mixture is required and only the driving heat of higher temperature like the exhaust gas heat can make it.

\section{HYBRID REFRIGERATION CYCLE}

Even if the temperature of driving heat is low like jacket water, it is possible to make cold energy below $-10^{\circ} \mathrm{C}$ by forcibly transferring the evaporated refrigerant to the absorber. Figure 1 shows the concept of the hybrid system. The absorber, regenerator, condenser, and the evaporator are the same as conventional absorption chiller. The difference is that a compressor is attached between the absorber and the evaporator. It is a part of a turbocharger. The turbine is driven by high pressure $\mathrm{NH}_{3}-\mathrm{H}_{2} \mathrm{O}$ vapor made by the exhaust gas heat. As the temperature of the spent vapor after turbine(2) in the figure) is about $130^{\circ} \mathrm{C}$, it is used to heat up the feed liquid to the regenerator(5) in the figure).

To adjust the torque balance between the turbine and the compressor, the previous paper [1] showed following two methods.

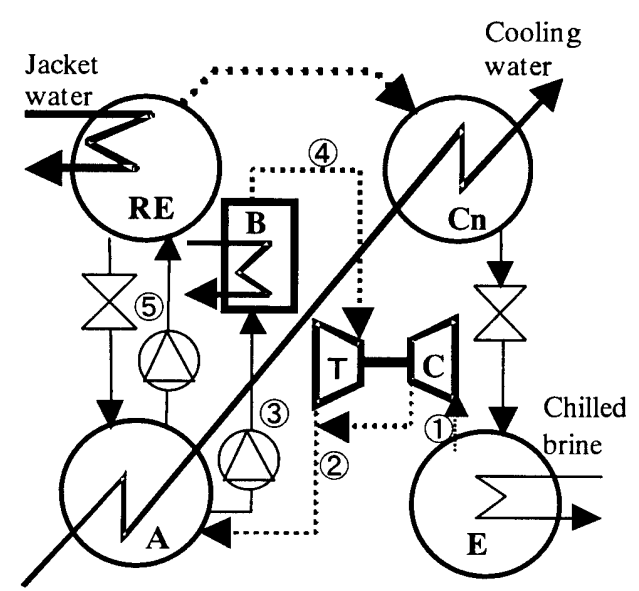
A: Absorber
B: Exhaust gas boiler
C: Compressor
$\mathrm{C}_{\mathrm{n}}$ : Condenser
E: Evaporator
RE: Regenerator

Fig. 1 Conceptual flow diagram of hybrid refrigerator

(a) Adjustment of the $\mathrm{NH}_{3}$ concentration in the absorber

(b) Mixing of the pure $\mathrm{NH}_{3}$ in the condenser $\mathrm{C}_{\mathrm{n}}$ into boiler feed liquid(3) in the figure).

Only the first method is adopted in the test system and the availability of the second method is proved by power generating system; the authors have also tested an electric power generating system by modifying this refrigerator after the refrigeration test, which will be reported in the near future.

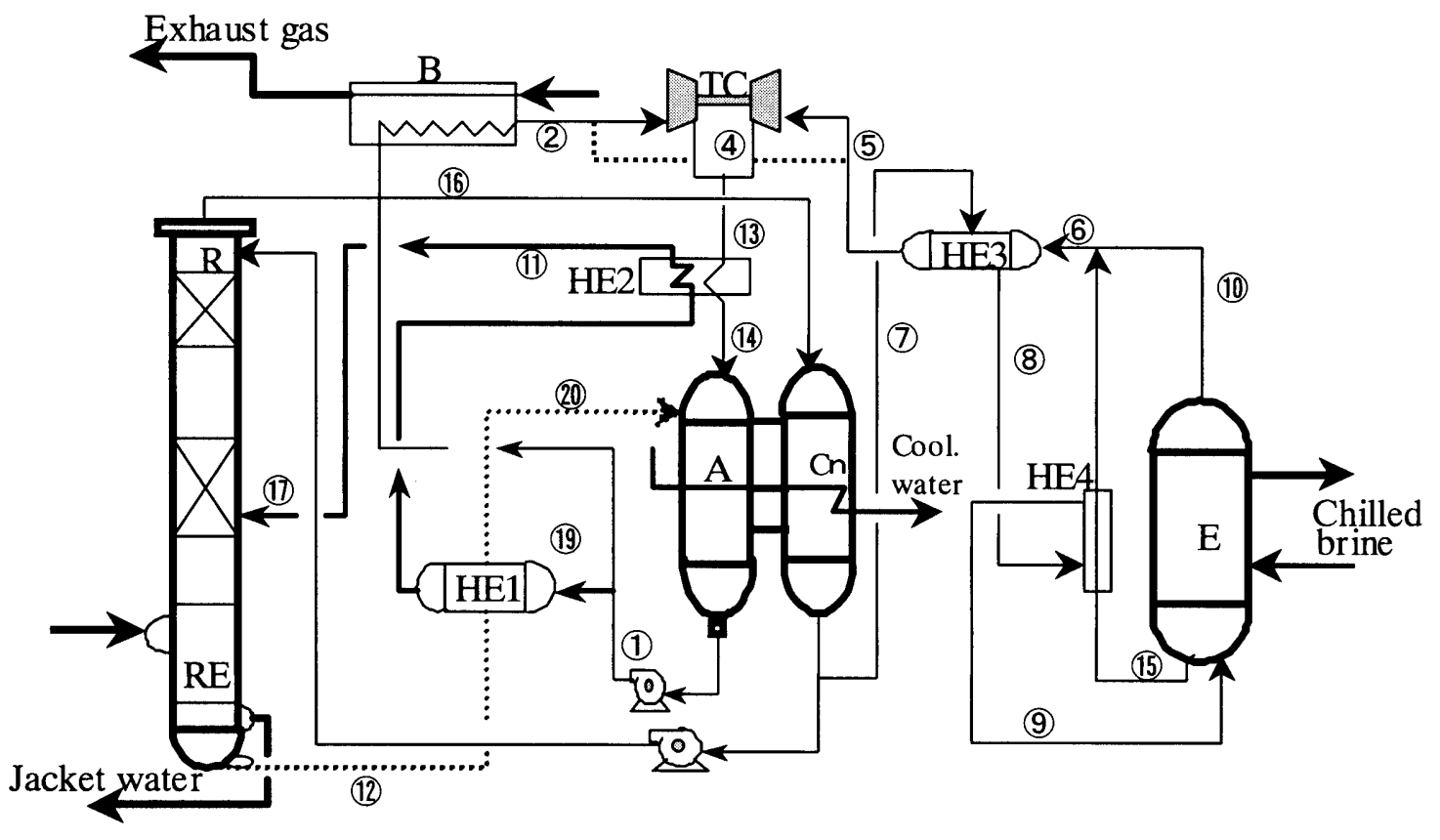
A: Absorber
B: Boiler
$\mathrm{C}_{\mathrm{n}}$ : Condenser
E: Evaporator
RE: Regenerator
$\mathrm{R}$ : Rectifying column HE1 HE4: Heat exchangers TC: Turbocharger

Fig. 2 Flow diagram of proposed hybrid refrigerator driven by gas engine exhaust heat 


\section{SYSTEM DESIGN}

\subsection{System}

Specifications of test utility are shown in Table 1. Figure 2 is the detail diagram of the hybrid refrigeration cycle. Figure 3 is a photo of the test facilities.

In Fig. 2 , HE1 $\sim$ HE 4 are heat exchangers. They are used for the following purposes.

HE1: Heat recovery from the liquid returning from the regenerator to the absorber

HE2: Heat recovery from the turbine spent vapor and compressor discharge vapor

HE3: Cooling down of liquid supply to the evaporator

HE4: Vaporization of water condensed in the evaporator

$\mathrm{NH}_{3}-\mathrm{H}_{2} \mathrm{O}$ liquid in the absorber is transferred to the regenerator $\mathrm{RE}$ through line (1)-(17). The $\mathrm{NH}_{3}$ vapor evaporates in RE. It is rectified to $99.8 \%$ in the rectifying column $R$, condenses in the condenser $C_{n}$, and is delivered to the evaporator $\mathrm{E}$ to do refrigeration(The route is $\mathrm{R}$-(16) - $\mathrm{C}_{\mathrm{n}}$-(7)-HE3-(8)-HE4-(9)-E). The evaporated refrigerant is compressed by the turbocharger. Then, after the heat is removed in HE2, it is transferred to the absorber(10)-(6) -HE3-(5)-TC-(4)-(13)-HE2-(14), and finally absorbed into the liquid returning from the regenerator(12)-HE1-(20). The high pressure vapor to drive the turbine is produced from exhaust gas boiler B. Turbine bypass line was added between (2) and (4) and compressor bypass line is added between (5) and (4). The former is used for power control as well as for starting up. The latter is used to avoid surge. The flow rate in the compressor bypass is controlled to keep the pressure ratio under the surge line, which is a function of compressor load. The exhaust gas and the jacket water are made by gas burners. Specifications of the exhaust gas are those of the actual $570 \mathrm{~kW}$ gas engine. However, jacket water is set $55 \%$ of the actual value due to budget restriction. To avoid corrosion, main parts of the system is made of stainless steel and turbine inlet temperature is set $300^{\circ} \mathrm{C}$. As to the exhaust gas boiler, natural circulation water tube boiler is adopted to secure the control stability. But the heating surface area of each heater is adjusted to optimize the heat recovery. Temperature difference at the pinch point is set $44{ }^{\circ} \mathrm{C}$.

\subsection{Turbocharger}

Considerations to following items were paid in designing the turbocharger.

(a) Materials to resist corrosion and fatigue.

(b) High peripheral velocity and high efficiency.

(c) High pressure ratio, small flow rate, and low specific speed.

(d) Reduction of leakage behind the blade and thrust.

(e) Realization of high load gas bearing.

(f) Vibration stability.

(g) Cooling of bearing, rotor, and casing

(h) Prevention of liquid condensation.

In case of ammonia compressor, the peripheral velocity must be 1.3 times higher than that of air compressor for the same pressure ratio. To attain the required pressure ratio, the peripheral velocity must be
Table 1 Specifications of test utility

\begin{tabular}{l|c}
\hline Exhaust gas & 13A gas burned at $\lambda=1.66$ \\
Fuel & $3221 \mathrm{~kg} / \mathrm{h}$ \\
Flow rate & $515{ }^{\circ} \mathrm{C}$ \\
Temperature & \\
Jacket water & $29326 \mathrm{~kg} / \mathrm{h}$ \\
Flow rate & $93 \rightarrow 88{ }^{\circ} \mathrm{C}$ \\
Temperature & \\
Brine & $-15 \rightarrow-20{ }^{\circ} \mathrm{C}$ \\
Temperature & \\
\hline
\end{tabular}

Turbocharger

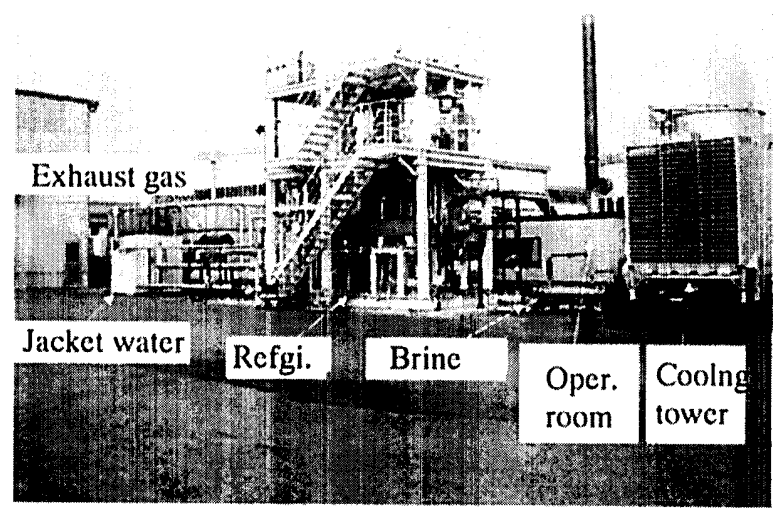

Fig. 3 Test facilities of hybrid refrigerator

about $530 \mathrm{~m} / \mathrm{sec}$. To resist the centrifugal force and the corrosion, 17-4 PH was adopted for the blade material. As to the turbine inlet pressure, 30 bar was selected in consideration of both turbine efficiency and thrust force. Although thermodynamic efficiency increases as the inlet pressure increases, turbine efficiency decreases in such a case. As the appropriate pressure is not necessarily high, optimal pressure must be calculated by simulation. To cope with the big thrust due to the pressure difference between the turbine inlet and the compressor inlet, a disk balancer was attached at the middle of the shaft.

As the temperature difference between the turbine inlet and the compressor inlet is large, the disk was made hollow to prevent the thermal conductivity. To reduce the leakage, labyrinth system with deliberate pressure balance was used. For the gas bearing, static gas bearing was adopted, and, to secure the necessary pressure while preventing the condensation, high pressure seal gas of $99.8 \% \mathrm{NH}_{3}$ concentration was supplied from condenser and heated up by jacket water.

Several problems such as vibration, thermal stress and flow were analyzed by computer simulation. Critical speed is set over design point.

Table 2 is its specifications. Figure 4 shows a photo of the turbocharger.

\section{TEST RESULTS}

\subsection{Turbocharger}


Table.2 Specifications of turbocharger

\begin{tabular}{l|l}
\hline Rotation & $13,5000 \mathrm{rpm}$ \\
Compressor & \\
Working fluid & $99.8 \% \mathrm{NH}_{3}$ vapor \\
Flow rate & $661.6 \mathrm{~kg} / \mathrm{h}$ \\
Inlet pressure & $1.58 \mathrm{bar}$ \\
Inlet temperature & $8{ }^{\circ} \mathrm{C}$ \\
Outlet pressure & $4.09 \mathrm{bar}$ \\
Turbine & \\
Working fluid & $54.0 \% \mathrm{NH} 3$ vapor \\
Flow rate & $604.3 \mathrm{~kg} / \mathrm{h}$ \\
Inlet pressure & $30 \mathrm{bar}$ \\
Inlet temperature & $300{ }^{\circ} \mathrm{C}$ \\
Outlet pressure & $4.09 \mathrm{bar}$ \\
\hline
\end{tabular}

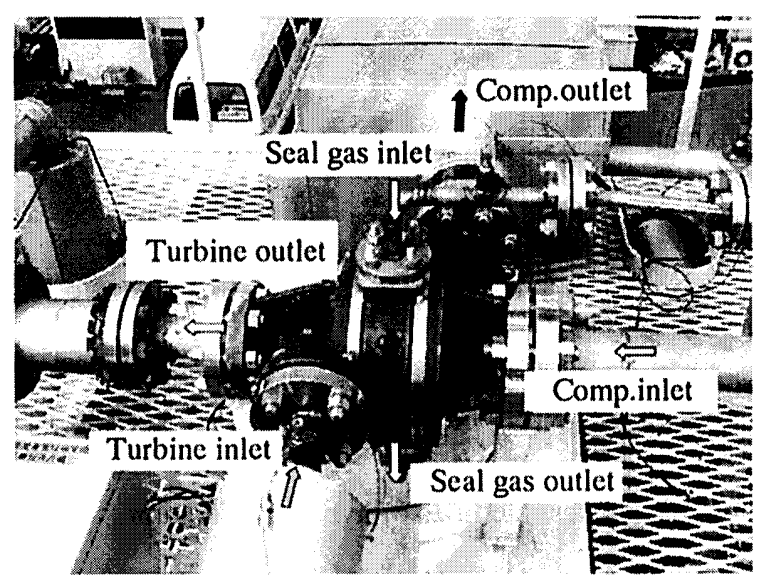

Fig. $4 \mathrm{NH}_{3}$ Turbocharger

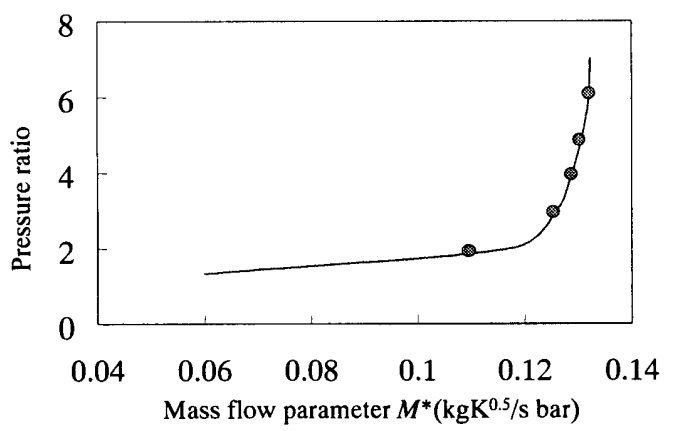

Fig. 5 Turbine characteristics

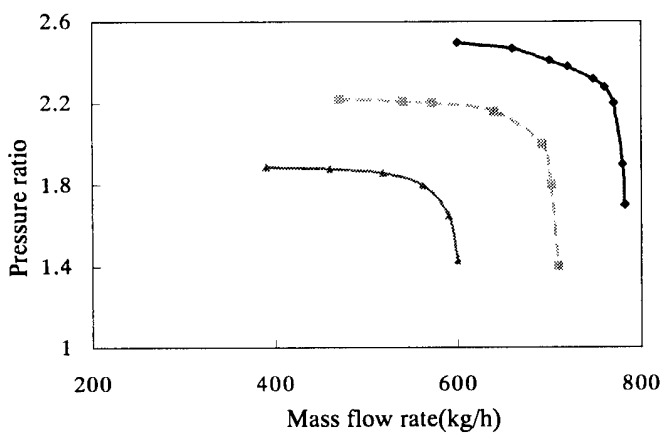

Fig.6 Compressor characteristics
As it is difficult to get the enough data by the refrigeration system, performance test by air was done independently. Figure 5 shows pressure ratio and mass flow parameter of the turbine and Fig. 6 shows pressure ratio and mass flow of the compressor. Mass flow parameter $M^{*}$ (a kind of Mach number) is defined as follows

$$
M^{*}=G \sqrt{T} / p
$$

These values were converted to those for $\mathrm{NH}_{3}$ property. In case of the compressor, pressure ratio at design point (135000rpm, $661.6 \mathrm{~kg} / \mathrm{h}$ ) was 2.48 , which is slightly lower than the design value (2.59). The efficiency (not shown) was $81 \%$, which is $8 \%$ higher than anticipated. As to the turbine, maximum measured pressure ratio was 6.2 and this value is lower than the design point value $7.33(\mathrm{U} / \mathrm{C}$ is 0.429 for reference). However, as the choking starts at 6.2 , the datum is available for the design point. The efficiency curve (not shown) also became flat at pressure ratio 5.6 and was $68 \%$ at the design point, which is $7 \%$ higher than anticipated. Mass flow parameter at design point was 0.135 , which is within the anticipation.

In the test system, it is also confirmed that the actual data well agrees with the lines in Fig5 and Fig.6.

\subsection{System}

Although the rated revolution of $135,000 \mathrm{rpm}$ was attained, the operation hour was not enough for us to confirm the data stable. So the authors estimated the data at $135,000 \mathrm{rpm}$ from the stable data at $125,000 \mathrm{rpm}$ by calculation. Adding to enthalpy/mass balances, following assumptions were used in the calculation.

(a) Turbocharger has characteristics in Fig.5 and Fig.6.

$$
\begin{aligned}
& p_{\text {tin }} / p_{a b s}=f_{t}\left(M^{*}{ }_{t}\right) \\
& p_{a b s} / p_{e v}=f_{c}\left(G_{c}\right)
\end{aligned}
$$

(b) Efficiencies in the following equation remain constant within a small region of calculation.

$$
\eta_{m} \eta_{t} W_{t}=W_{c} / \eta_{c}
$$

(c) Heat transfer at heat exchanger is proportional to logarithmic mean temperature difference

$$
Q=h A \Delta t_{m}
$$

The results are not so much different from the real data at $135,000 \mathrm{rpm}$. Parts of them are shown in table 3 for the comparison with the design values. Although sensors are fitted with care, errors within $2 \%$ or so seem to be inevitable. Refrigerant supply to the evaporator is $4.3 \%$ smaller than the design value, but the cooling capacity is about $17 \%$ higher than anticipated. The reason is supposed to be due to the following differences from design data.

(a) Liquid supply rate to HE4 from the evaporator

(b) Effect of sensible heat of refrigerant on heat exchange in the evaporator

(c) Evaporating pressure

The efficiencies of turbine and compressor are higher 
Table. 3 Design values and test results

\begin{tabular}{l|cc}
\hline Items & Design values & Test results \\
\hline Cooling capacity & $214 \mathrm{~kW}$ & $250.4 \mathrm{~kW}$ \\
Recovered heat & & \\
Exhaust gas & $439.7 \mathrm{~kW}$ & $464.1 \mathrm{~kW}$ \\
Jacket water & $170.5 \mathrm{~kW}$ & $155.7 \mathrm{~kW}$ \\
Regenerator & & \\
Vaporized NH3 & $796.5 \mathrm{~kg} / \mathrm{h}$ & $973 \mathrm{~kg} / \mathrm{h}$ \\
Temperature & $83{ }^{\circ} \mathrm{C}$ & $92{ }^{\circ} \mathrm{C}$ \\
Pressure & $10.97 \mathrm{bar}$ & $11.0 \mathrm{bar}$ \\
Evaporator & & \\
Ref. supply rate & $661.6 \mathrm{~kg} / \mathrm{h}$ & $633.4 \mathrm{~kg} / \mathrm{h}$ \\
Temperature & $-24{ }^{\circ} \mathrm{C}$ & $-24.6{ }^{\circ} \mathrm{C}$ \\
Pressure & $1.58 \mathrm{bar}$ & $1.42 \mathrm{bar}$ \\
Turbine inlet & & \\
Temperature & $300{ }^{\circ} \mathrm{C}$ & $284.1{ }^{\circ} \mathrm{C}$ \\
Pressure & $30 \mathrm{bar}$ & $22 \mathrm{bar}$ \\
Steam supply & $604.3 \mathrm{~kg} / \mathrm{h}$ & $655.4 \mathrm{~kg} / \mathrm{h}$ \\
Turbine efficiency & 0.61 & 0.65 \\
Comp. efficiency & 0.72 & 0.79 \\
\hline
\end{tabular}

than the design value, but lower than the results by air test. This is perhaps the problem of assembly; the turbine was assembled several times due to the failure of gas bearing. As the efficiency of the turbocharger was higher than anticipated, turbine bypass was controlled to make the turbo balance, which resulted in lower turbine inlet pressure (22 bar). The bypass flow increases the exhaust heat recovery in HE2. This is the reason why vaporized $\mathrm{NH}_{3}$ in the regenerator $(973 \mathrm{~kg} / \mathrm{h})$ is larger than the planned value $(796.5 \mathrm{~kg} / \mathrm{h})$. Part of the vaporized $\mathrm{NH}_{3}$ from the generator is used for gas bearing/seal system. As the bearing/seal system consumed more vapor than the design value, supply to the evaporator becomes smaller than the design value. These facts indicate that by deliberate design, the capacity will be much higher. Nevertheless, the capacity is 1.97 times higher than conventional single effect absorption system (The conventional system is assumed to be driven by 1.8 bar steam produced by exhaust gas.).

\section{APPLICATION TO SPACE COOLING/HEATING}

As the hybrid concept is proved to be attainable, the authors investigated the possibility of the application to space heating/cooling by simulation based on enthalpy and mass balance. Concerning the turbocharger efficiency and heat exchanger performance, test results were used for reference. In actual applications, turbocharger efficiencies might be higher because the pressure ratios are lower than in the case of $-20^{\circ} \mathrm{C}$

\subsection{Space cooling}

Figure 7 shows the relationship between COP and output temperature. COP is defined by the cooling capacity divided by the recovered exhaust heat by conventional system; instead of actual recoverable heat, standard value is used for the denominator for easiness of comparison. In the diagram, Case 1 is the system with a rectifier. Case 2 is a system without rectifier. Case 3 is same as Case 2, except

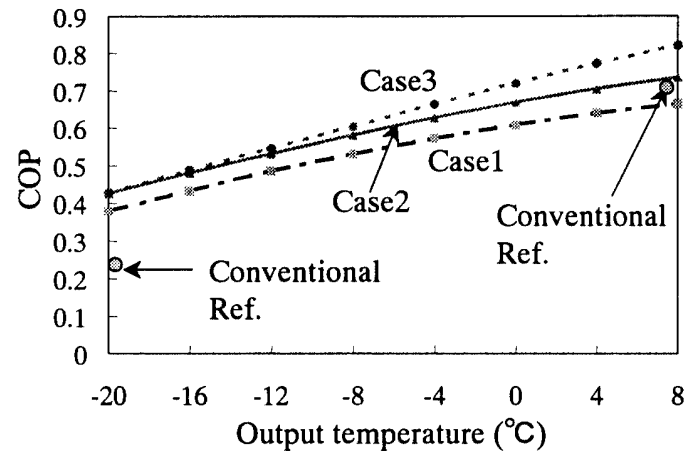

Fig. 7 COP and output temperature in cooling

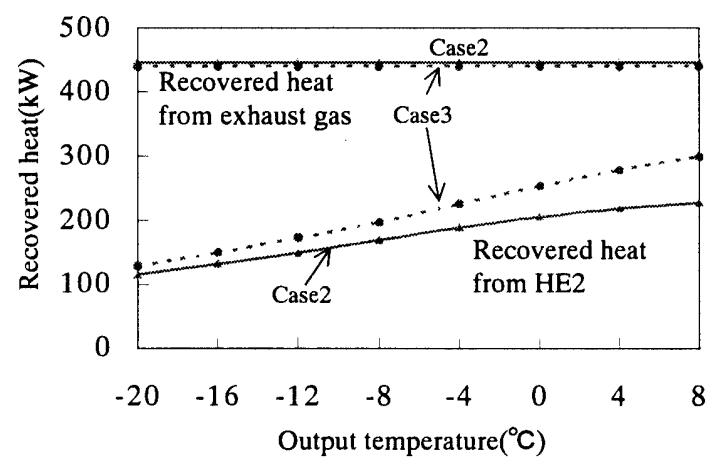

Fig. 8 Recovered heat from exhaust gas and HE2

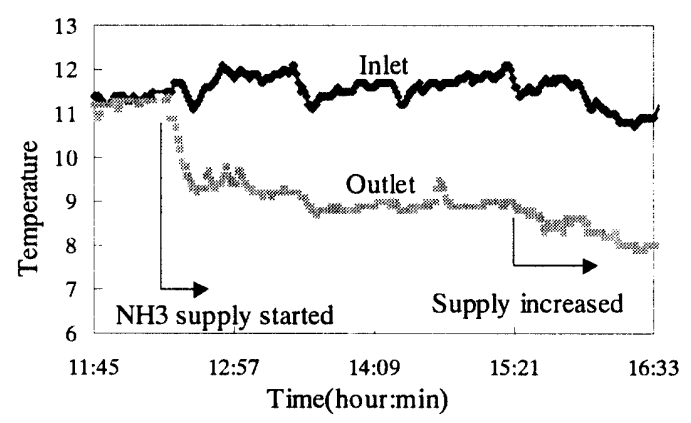

Fig.9 Brine temperature and time elapsed

that exhaust gas boiler feed liquid is supplied from regenerator return flow(20) in Fig. 2). The performance increases in this order. COP of conventional single effect absorption system on the market are also shown for reference. Those of conventional system and hybrid system at $-8^{\circ} \mathrm{C}$ are 0.68 and 0.82 respectively. The discrepancy is relatively small because, at $-8^{\circ} \mathrm{C}$, conventional chiller can also use jacket water as well as exhaust gas. Case 2 and Case 3 have almost same capacity at $-20^{\circ} \mathrm{C}$. But as the temperature increases, performance of Case 3 becomes higher than that of Case 2. The reason is that, in Case 3, as the concentration of the turbine vapor is lower than that in Case 2, larger heat recovery from the turbine exhaust is possible due to vapor condensation in HE2. Fig. 8 shows the comparison between Case 2 and Case 3 in heat recovery. Recovered heats from the exhaust gas are almost same, but as to recovered heat from HE2, Case 3 is larger than Case 2. As referred above, Case 2 and Case 3 have no rectifier. It is because, in case of space cooling application, rectifier may 


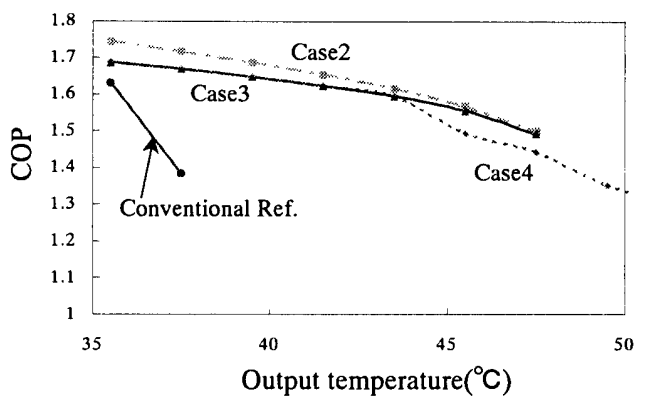

Fig. $10 \mathrm{COP}$ and output temperature in heating

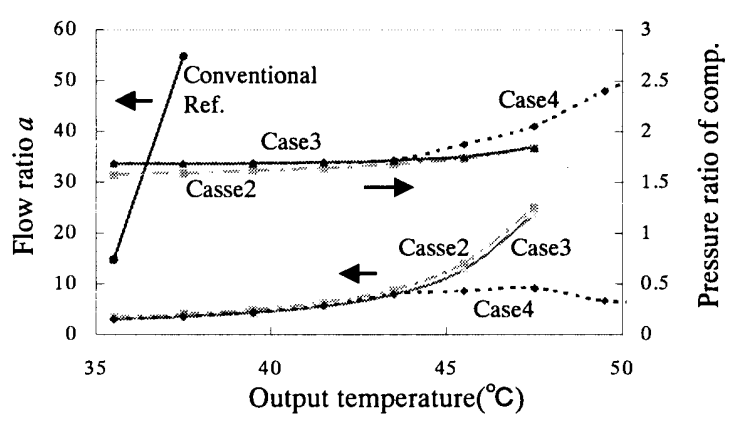

Fig.11 Flow ratio/pressure ratio vs. output temperature

not be needed. To confirm the needlessness, independent test was done. Figure 9 shows the inlet/outlet brine temperature vs. the operation hours of an evaporator, where $92.5 \%$ refrigerant is supplied without rectifier. The brine flow rate is kept constant and the evaporated vapor is to be absorbed into the absorber of $27.2 \%$ concentration. The system keeps almost constant temperature for hours as long as refrigerant is fed constantly, which indicates the needlessness of a rectifier in application to space cooling.

\subsection{Space heating}

Figure 10 shows the relationship between COP and output temperature when the system is used as the first kind heat pump in which cooling water is used as heat output media. Case 2 and Case 3 are same as in Fig.7. Case 4 is the same system as Case 2 except that concentration of the boiler feed liquid is increased by injecting the refrigerant in the condenser to suppress the flow ratio $a$ below 10 . The temperature of the heat sink is assumed $5^{\circ} \mathrm{C}$. The rugged curve of Case 4 is due to the stepwise change of mixing ratio in calculation process. Figure 11 shows the flow ratio and compression pressure ratio of the heat pump. The flow ratio $a$ is a ratio of the produced vapor to the liquid supplied to the regenerator and is often used as an indicator of the regenerator size. On the other hand, pressure ratio is needed to design compressor. By conventional system, COP decreases drastically and the flow ratio increases rapidly with the increase of the output temperature. It means that it is impossible to use the conventional exhaust heat chiller as a heat pump. It is because of the constraint of concentration balance in the cycle, which is one of the big defects of the absorption system. In contrast, it is possible to get high temperature up to $50^{\circ} \mathrm{C}$ by Case 4 , while suppressing the flow ratio below 10 and the pressure ratio below 2.5

\section{CONCLUSIONS}

A turbo-charger integrated absorption system, so called hybrid refrigeration system, has been developed to produce cold energy of $-20^{\circ} \mathrm{C}$ and tested. The test result proved that the capacity of the new system is about twice of that of the conventional system driven by the steam extracted from exhaust gas boiler. The simulation followed by the test results also showed that, if the concept is applied to space cooling/heating, COP is 0.82 at $8^{\circ} \mathrm{C}$ in cooling mode, and $1.7 \sim 1.3$ at $40{ }^{\circ} \mathrm{C} \sim 50{ }^{\circ} \mathrm{C}$. Such a high performance is due to the liberation of the restraint of the concentration balance in absorption cycle by introducing turbocharger inside the system. Although it is not shown in the paper, the system can be easily modified to a super efficient electric power generating system. One of the other advantages of the concept is that the mode of the output (cooling, heating and power generation) is made exchangeable with each other with slight modifications, which means it is possible to operate the system optimally in accordance with the demands pattern to increase the annual availability of the energy.

\section{REFERENCES}

1. Fujimoto et al., Gas Engine Exhaust Heat Refrigeration Cycle Using Ammonia/Water Mixture, 3 rd International Symposium on Advanced Energy Conversion Systems and Related Technologies (2001) , 2-A-5.

2. T. Karimata et al., Hybrid Compression/Absorption Type Heat Utilization System, Heat Pumps Systems $35,6^{\text {th }}$ IEA Heat Pump Conference(1999)

3. Gy. Bergmann, G. Hivessy, Volume E. 251, Proceedings of $\mathrm{XVI}{ }^{\text {th }}$ International Congress of Refrigeration

\section{<NOMENCLATURE>}

$a$ : flow ratio [dimensionless]

$G:$ mass flow rate $[\mathrm{kg} / \mathrm{s}]$

$h$ : heat transfer coefficient $\left[\mathrm{kJ} / \mathrm{Km}^{2} \mathrm{~s}\right]$

$M^{*}$ : mass flow parameter $\left[\mathrm{kg} \mathrm{K}^{0.5} / \mathrm{s}\right.$ bar]

$Q:$ heat transfer $[\mathrm{kJ} / \mathrm{s}]$

$T: \quad$ temperature $[\mathrm{K}]$

$p: \quad$ pressure [bar]

$U / C:$ blade speed ratio [dimensionless]

$W: \quad$ adiabatic work $[\mathrm{kJ} / \mathrm{s}]$

$\Delta t m: \quad$ logarithmic mean temperature difference [K]

$\eta$ : adiabatic efficiency [dimensionless]

abs: absorber c: compressor ev: evaporator

$\mathrm{m}$ : mechanic tin: turbine inlet $t$ : turbine 